\title{
Model Penerapan Etika Pelayanan Pekerja Wanita Spa Pada Hotel Berbintang Di Desa Adat Seminyak
}

\author{
Putu Diah Kesumadewi' ${ }^{1}$ A.A. Manik Pratiwi ${ }^{2}$ \\ Program Studi Diploma IV, Fa kultas Pariwisata, Universitas Udayana, \\ Jln. DR.R.Goris.f.par@unud.ac.id \\ diahkusumadewi@unud.ac.id ${ }^{1}$, manikpratiwi@unud.ac.id ${ }^{2}$
}

\begin{abstract}
Abstrak
Industri pariwisata mengalami perkembangan yang pesat di Indonesia saat ini. Ini terbukti da ri makin meningkatnya jumlah usaha-usaha pariwisata yang didirikan di hampir seluruh wilayah di Indonesia. Kumpulan usaha pariwisata ini saling terkait satu sama lain dalam menyediakan kebutuhan wisatawan agar merasa nyaman untuk tinggal di tempattersebut. Usaha pariwisa ta meliputi daya tarik wisa ta, kawasan pariwisa ta, jasa transportasi wisata, jasa perjalanan wisata, jasa makanan dan minuman, penyediaan akomodasi, penyelenggaraan ke gia tan hibu ran dan rekreasi, SPA ( da n sebagainya). SPA menjadi salah satu usaha pariwisa ta yang berkembang pesat saat ini, dikarenakan SPA adalah termasuk dalam kegiatan wisa ta kesehatan. Hotel berbintang turut andil da lam meningkatkan penyelenggara an usaha pariwisa ta SPA melalui penyediaan usaha ini da lam jasa penyelenggaraan usaha di hotel. Etika pelayanan pekerja wa nita SPA pada hotel berbintang diDesa Adat Seminyak harus diterapkan dalam opera sional kerja di hotel tersebut. Dengan adanyaetika pelayanan yang baik maka wisa tawan yang menikmati ja sa ini a kan merasa puas sehingga tidak menutup kemungkinan a kan berdampak positif bagi sektor usaha lainny a yang a da dihotel tersebut.

Penelitian ini menggunakan metode deskriptif, yaitu suatu metode yang digunakan unt uk memperoleh gambaran dari tujuan penelitian. Untuk menganalisis tanggapan/persepsi wisa ta wan terhadap Etika pelayanan pekerja wa nita SPA digu nakan Skala Likert, me lalui peny ebaran kuesioner kepada wisatawan yang dijadikan responden.

Hasil penelitian model penerapan etika pelayanan pekerja wanita SPA pada hotel berbintang di Desa Adat Seminyak terdiriatas 3 tahapan, tahapan pertama yakni etika pelayanan tamu sebelum perawatan ditinjau dari a spek tangible atau fisik dan relia bility a tau ke andalan. Tahapan kedua yakni etika pelayanan tamu selamaperawatan ditinjau dari aspek as su ran ce atau jaminan dan empathy atau perhatian. Ta hapan ketiga y akniresponsiveness a tau daya tanggap.
\end{abstract}

Ka ta kunci: Etika, Pela yanan, Pekerja Wanita, SPA

\begin{abstract}
The tourism industry is experiencing rapid development in Indonesia today. This is evident from the increasing number of tourism businesses established in a lmost all region $\mathrm{s}$ in Indonesia. This collection of tourism businesses is interrelated with each other in providing the needs of tourists to feel comfortable to live in that place. Tourism businesses include tourist attractions, tourism areas, tourism transportation services, travel services, food a nd beverage services, accommodation, organizing entertainment and recreational activities, SPA, etc. SPA has become one of the fastest growing tourism businesses today, because SPA is in clu ded in hea lth tourism activities. Star hotels contribute to improving the operation of SPA to urism bu sinesses through the provision of this business in business administration servic es at hotels. The ethic s services of female SPA workers in star-rated hotels in the Tra ditional Village of Seminyak must be applied in the operational work of the hotel. With the existence of good service ethics, tourists who enjoy this service will feel satisfied so that it will not close the possibility of having a positive impact on other business sectors in the hotel.

This resea rch uses descriptive method, which is a method used to obtain an overvie w of the resea rch objectives. To a nalyze tourists responses/perceptions of the ethics of female work ers' services SPA used a Likert Scale, by distributing questionnaires to tourists who were made respondents.

The results of the research model on the application of the ethics of female SPA service workers to star hotels in Seminyak Tra ditional Village consists of 3 stages, the first stage is the
\end{abstract}


ethics of guest service before treatment in terms of tangible or physical a spects and relia bility or reliability. The second stage is the ethics of guest service during treatment in terms of a ssurance or a ssurance and empathy or a ttention. The third stage is responsiveness or responsiv eness.

Keywords: Ethics, Services, Women Workers, SPA

\section{PENDAHULUAN}

Industri pariwisata mengalami perkembangan yang pesat di Indonesia saat ini. Ini terbukti dari makin meningkatnya jumlah usaha-usaha pariwisata yang didirikan di hampir seluruh wilayah di Indonesia. Dikutip dari halaman website www.goodnewsfromindonesia.id (2017), dikatakan bahwa terhitung 2017, industri pariwisata menempati peringkat kedua terbesar dalam sumbangan devisa di Indonesia. Itu sebabnya pariwisata kini menjadi industri yang sangat diperhatikan kualitasnya agar mendapat perhatian dunia internasional. Dengan meningkatkan kualitas pariwisata maka diharapkan berdampak positif bagi perkembangan pariwisata Indonesia di dunia internasional.

Menurut Undang-Undang Pariwisata No. 10 Tahun 2009, Industri Pariwisata adalah kumpulan usaha pariwisata yang saling terkait dalam rangka menghasilkan barang dan/atau jasa bagi pemenuhan kebutuhan dalam penyelenggaraan pariwisata. Kumpulan usaha pariwisata ini saling terkait satu sama lain dalam menyediakan kebutuhan wisatawan agar merasa nyaman untuk tinggal di tempat tersebut. Usaha pariwisata meliputi daya tarik wisata, kawasan pariwisata, jasa transportasi wisata, jasa perjalanan wisata, jasa makanan dan minuman, penyediaan akomodasi, penyelenggaraan kegiatan hiburan dan rekreasi, SPA ( dan sebagainya). Keterkaitan usaha pariwisata ini satu sama lain diharapkan dapat berlangsung dengan baik sehingga penyelenggaraan pariwisata dapat berlangsung dengan baik pula.

Penyelenggaraan usaha pariwisata di suatu daerah harus didukung oleh pemerintah agar dapat bersaing secara sehat. Persaingan yang sehat antar usaha pariwisata dapat menciptakan iklim usaha yang baik bagi pariwisata di daerah tersebut. Dari semua usaha pariwisata yang telah disebutkan, beberapa usaha merupakan usaha yang tergolong baru dikembangkan pada beberapa tahun belakangan ini. Salah satu usaha yang dimaksud adalah usaha pariwisata SPA. SPA menjadi salah satu usaha pariwisata yang berkembang pesat saat ini, dikarenakan SPA adalah termasuk dalam kegiatan wisata kesehatan. Hotel berbintang turut andil dalam meningkatkan penyelenggaraan usaha pariwisata SPA melalui penyediaan usaha ini dalam jasa penyelenggaraan usaha di hotel.

Hotel berbintang di Desa Adat Seminyak termasuk bagian dalam hotel yang menyediakan jasa usaha SPA di dalamnya. Pendapatan SPA menjadi salah satu sumber pendapatan yang ditargetkan oleh beberapa hotel berbintang di Desa Adat Seminyak. Ini dikarenakan banyak hotel berbintang yang memasukkan produk SPA dalam mempromosikan produk hotel kepada pelanggan hotel dalam hal ini wisatawan. Pemasaran hotel memasukkan produk SPA ke dalam bagian promosinya. Bahkan bagi beberapa hotel berbintang memasarkan produk SPA tidak hanya bagi wisatawan yang menginap di hotelnya namun juga kepada wisatawan yang menginap di hotel yang lain. Hal ini membuktikan bahwa usaha jasa SPA berpengaruh bagi pendapatan usaha hotel berbintang di Desa Adat Seminyak.

Penyelenggaraan usaha jasa SPA di hotel berbintang di Desa Adat Seminyak sangat ditentukan dari kualitas pelayanan yang diberikan oleh pekerja di usaha ini. Kebanyakan pekerja usaha SPA adalah tergolong pekerja wanita. Pekerja wanita dinilai lebih cocok bekerja di sektor usaha ini daripada pekerja pria. Untuk itu sebagian besar pekerja SPA merupakan pekerja wanita. Wanita memiliki kemampuan yang lebih baik dalam bekerja di sektor usaha SPA. Untuk itu banyak wanita yang dipekerjakan pada sektor usaha SPA, begitupula pada SPA pada hotel berbintang di Desa Adat Seminyak. 
Pekerjaan di sektor usaha SPA di hotel berbintang sangat dipengaruhi oleh berbagai macam aturan. Aturan ini mengikat dan mengatur pekerja wanita SPA dalam melakukan prosedur kerja di SPA. Aturan ini erat kaitannya dengan etika pelayanan yang cocok diterapkan pada pekerja wanita SPA. Bekerja pada sektor usaha SPA pada hotel berbintang di Desa Adat Seminyak tentu saja memerlukan etika pelayanan yang baik. Hal ini berpengaruh bagi keberlangsungan usaha SPA pada hotel berbintang di Desa Adat Seminyak.

Etika pelayanan pekerja wanita SPA pada hotel berbintang di Desa Adat Seminyak harus diterapkan dalam operasional kerja di hotel tersebut. Dengan adanya etika pelayanan yang baik maka wisatawan yang menikmati jasa ini akan merasa puas sehingga tidak menutup kemungkinan akan berdampak positif bagi sektor usaha lainnya yang ada di hotel tersebut. Maka dari itu patut kiranya untuk diketahui bagaimana model penerapan etika pelayanan yang sesuai bagi pekerja wanita SPA pada hotel berbintang di Desa Adat Seminyak agar wisatawan yang menggunakan jasa ini dapat merasa puas sehingga akan berkunjung untuk menggunakan jasa ini kembali.

Berdasarkan latar belakang tersebut maka permasalahan dalam penelitian ini adalah : "Bagaimanakah model penerapan etika pelayanan pekerja wanita SPA pada hotel berbintang di Desa Adat Seminyak?" Adapun tujuan penelitian ini adalah untuk mengetahui model penerapan etika pelayanan pekerja wanita SPA pada hotel berbintang di Desa Adat Seminyak.

\section{METODE PENELITIAN}

Penelitian ini dilakukan di 5 ( lima ) hotel - hotel bintang 5 yang ada di kawasan Seminyak Bali yaitu : Anantara Seminyak Bali Resort \& Spa, The Royal Beach Seminyak Bali, Courtyard by Marriott Bali Seminyak Resort, Double Six Luxury Hotel Seminyak, Hotel Indigo Bali Seminyak Beach. Analisis dalam penelitian ini dilakukan dengan metode deskriptif, yaitu suatu metode yang digunakan untuk memperoleh gambaran dari tujuan penelitian. Model Etika Pelayanan pekerja wanita SPA pada hotel berbintang di Desa Adat Seminyak dijelaskan dengan memberikan gambaran atas penelitian yang dilakukan di lapangan.

Adapun definisi operasional variabel dari penelitian ini adalah sebagai berikut : Etika Pelayanan, yang dimaksud dalam penelitian ini adalah etika (1) sebagai nilai-nilai moral dan norma-norma moral yang menjadi pegangan bagi seseorang atau suatu kelompok dalam mengatur tingkah lakunya, atau disebut dengan "sistim nilai"; (2) sebagai kumpulan asas atau nilai moral yang sering dikenal dengan "kode etik"; dan (3) sebagai ilmu tentang yang baik atau buruk bagi pekerja wanita SPA pada hotel berbintang di Desa Adat Seminyak.

Variabel etika pelayanan pekerja wanita SPA ditinjau dari aspek pelayanan yaitu: 1)Bukti Fisik atau Bukti Langsung (tangible) Penampilan dan kemampuan sarana dan prasarana fisik harus dapat diandalkan. 2) Keandalan (reliability) Suatu kemampuan untuk memberikan jasa yang dijanjikan dengan akurat dan terpercaya. 3) Daya Tanggap (responsivenes) Suatu kebijaksanaan untuk memberikan layanan yang cepat kepada pelanggan, tidak membiarkan konsumen menunggu tanpa adanya suatu alasan yang jelas yang menyebabkan persepsi yang negatif dalam kualitas pelayanan. 4) Jaminan (assurance) Pengetahuan dan keramahan serta kemampuan melaksanakan tugas secara spontan yang dapat menjamin kinerja yang baik sehingga menimbulkan kepercayaan dan keyakinan pelanggan. 5) Empati (emphaty) Memberikan perhatian yang bersifat individual atau pribadi kepada pelanggan dan berupaya untuk memahami konsumen. 


\section{HASIL DAN PEMBAHASAN}

\subsection{Gambaran Umum Penelitian}

Kelurahan Seminyak terdiri atas empat lingkungan/banjar dinas dan dua banjar adat yang diempon oleh dua desa adat yang berbeda. Keempat banjar dinas pada kelurahan ini antara lain: Lingkungan/Banjar Seminyak, Lingkungan/Banjar Basangkasa, Lingkungan/Banjar Jimbaran Carik dan Lingkungan/Banjar Tagtag. Kelurahan ini terdiri atas dua desa adat, yaitu Desa Adat Seminyak (Banjar Adat Seminyak) secara keseluruhan dan sedikit wilayah Desa Adat Kerobokan (Banjar Adat Basangkasa). Wilayah Seminyak merupakan wilayah yang strategis karena dapat menjangkau berbagai tempat wisata dengan mudah. Hal ini menarik minat wisatawan untuk memilih hotel di kawasan ini sebagai akomodasi penginapannya.

\subsection{Model Penerapan Etika Pelayanan Pekerja Wanita SPA Pada Hotel Berbintang Di Desa Adat Seminyak}

Hotel-hotel bintang 4 dan bintang 5 di Kawasan Seminyak yang menjadi sampel dalam penelitian ini yaitu Anantara Seminyak Bali Resort \& Spa, The Royal Beach Seminyak Bali, Courtyard by Marriott Bali Seminyak Resort, Double Six Lux ury Hotel Seminyak, Hotel Indigo Bali Seminyak Beach umumnya adalah hotel yang memiliki fasilitas mewah

Berdasarkan hasil wawancara kepada pihak SPA pada hotel berbintang di Desa Adat Seminyak penerapan Etika Pelayanan diterapkan pada 5 dimensi kualitas pelayanan yakni:

1. Bukti Fisik atau Bukti Langsung (tangible)

Penerapan etika pelayanan pekerja wanita SPA pada hotel berbintang di Desa Adat Seminyak ditinjau dari aspek tangible dapat dilihat langsung dari penampilan area kerja serta fisik pekerja wanita SPA. Hal ini sangat diperhatikan oleh pihak hotel khususnya bagian SPA. Penerapan ini dilakukan untuk menarik minat tamu untuk berkunjung ke SPA. Penampilan area kerja serta fisik yang baik pada pekerja wanita SPA menunjukkan bahwa pekerja tersebut sudah mempersiapkan diri sebelum memulai pekerjaannya untuk melayani tamu di SPA.

Persiapan sebelum memulai pekerjaan yang dilakukan oleh pekerja wanita SPA pada hotel berbintang di Desa Adat Seminyak antara lain:

Persiapan area kerja, meliputi:

- Mempersiapkan ruangan kerja SPA dengan turut serta menjaga kebersihan dan kerapian ruangan. Walaupun housekeeping bertugas untuk membersihkan ruangan SPA, namun secara etika pekerja wanita SPA harus turut serta menjaga kebersihan dan kerapian area ruangan SPA. Pekerja wanita secara etika juga harus memperhatikan area kerja dimana pelayanan SPA itu akan dilaksanakan. Ini dikarenakan, terkadang tamu

Persiapan pribadi, meliputi:

Seorang pekerja wanita SPA dituntut untuk memiliki etika penampilan yang baik dalam melakukan pelayanan kepada tamu. Hal ini dapat dilakukan dengan menerapkan hal-hal sebagai berikut:

- Menjaga sanitasi diri dengan cara mandi minimal 2 kali sehari, menggosok gigi minimal 2 kali sehari serta mencuci rambut minimal 2 hari sekali.

- Selanjutnya mempergunakan pakaian seragam yang ditetapkan oleh ketentuan hotel yang bersangkutan. Seragam yang dipakai merupakan seragam yang telah dicuci bersih. Seragam dapat diambil pada ruangan linen serta diganti pada ruangan loker karyawan. Apabila seragam yang digunakan pada saat bekerja kotor diakibatkan terkena sesuatu saat melakukan pelayanan kepada tamu, maka seragam tersebut harus diganti dengan seragam yang bersih. Seragam yang dikenakan oleh pekerja wanita SPA pada hotel berbintang di Desa Adat Seminyak sebagian besar menggunakan baju atasan baik 
berbahan katun maupun berbahan kaos serta celana panjang. Seragam ini diharapkan mempermudah ruang gerak pekerja dalam melayani tamu.

Persiapan alat serta bahan operasional SPA, meliputi:

- Penataan alat SPA yang baik dan benar untuk digunakan selama layanan SPA berlangsung. Secara etika penataan ini dilakukan secara baik dan benar sesuai dengan prosedur yang telah ditetapkan. Hal ini tergantung dari layanan SPA yang ditawarkan. Jika alat yang tidak dibutuhkan selama layanan berlangsung maka alat tersebut sebaiknya disimpan pada tempat yang seharusnya. Jika alat-alat diletakkan secara tidak benar maka akan mengganggu layanan SPA yang sedang berlangsung. Berikut dapat dilihat kategori peralatan yang dipergunakan dalam pelayanan SPA:

o Peralatan sederhana:Shower, bathtub, steamer, facial secara manual

o Peralatan sedang: Aqua medic pool (jaccuzzi, bathtub), steamer/sauna, electric blanket, electric massage sederhana, facial equipment

o Peralatan kompleks: Aqua medic pool (jaccuzzi, whirlpool), hidrotub (air \& water jet), steamer/sauna, electric massage, great shower

Semua alat tersebut harus selalu digunakan dalam keadaan bersih sehingga pekerja wanita SPA di hotel berbintang di Seminyak harus menjaga kebersihan alat tersebut.

\section{Keandalan (reliability)}

Etika Pelayanan dalam menerapkan kemampuan pekerja wanita SPA pada hotel berbintang di Desa Adat Seminyak untuk memberikan jasa yang dijanjikan dengan akurat dan terpercaya. Hal ini ditunjukkan dengan melakukan layanan secara tepat waktu tanpa ada kesalahan. Pekerja wanita SPA pada hotel berbintang di Desa Adat Seminyak sangat memperhatikan waktu pelayanan. Mereka selalu menyediakan alat penanda waktu dalam melakukan layanan. Misalnya dalam melakukan perawatan body massage yang biasanya ditempuh selama 1 jam, mereka melakukan sesuai dengan standar waktu sesuai standar prosedur yang telah ditetapkan oleh hotel tersebut.

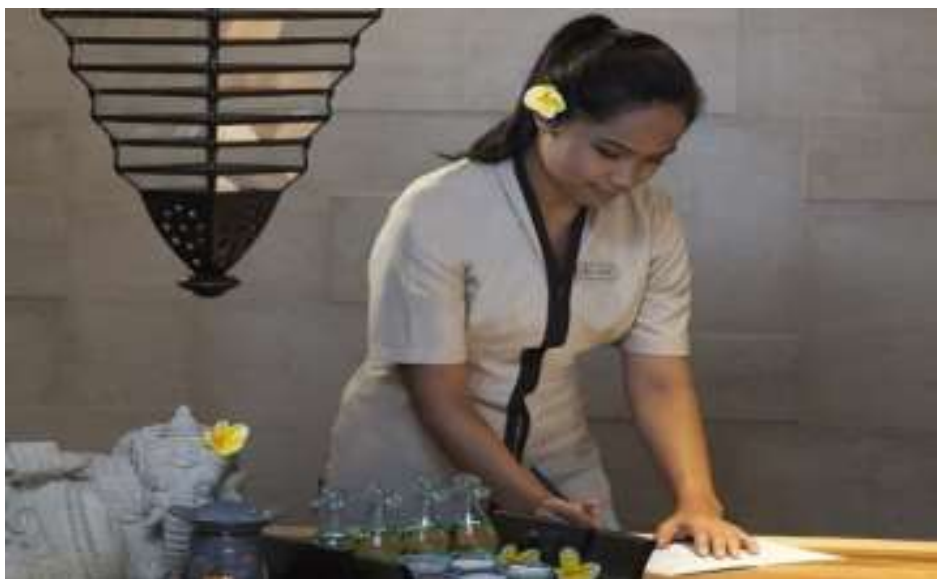

\section{Gambar 3.1 Keandalan Pekerja Wanita Spa Saat Persiapan Penerimaan Tamu Sumber: Penelitian 2018}

Sesuai Gambar 4.8 tampak seorang pekerja SPA di salah satu hotel berbintang di Desa Seminyak sedang memeriksa daftar pesanan tamu yang akan menggunakan fasilitas SPA. Pemeriksaan tersebut dilakukan agar pelayanan SPA dapat berlangsung dengan tepat waktu. Apabila tamu yang memesan belum datang sesuai dengan waktu yang disepakati maka petugas SPA akan segera menghubungi tamu tersebut untuk memastikan kepastian waktu layanan yang diinginkan. 


\section{Daya Tanggap (responsivenes)}

Penerapan etika pelayanan dengan aspek daya tanggap dapat dilihat dari kebijaksanaan pihak pekerja wanita SPA untuk memberikan layanan yang cepat kepada pelanggan, tidak membiarkan konsumen menunggu tanpa adanya suatu alasan yang jelas yang menyebabkan persepsi yang negatif dalam kualitas pelayanan. Pada peristiwa pelayanan gagal, kemampuan untuk segera mengatasi hal tersebut secara profesional dapat memberikan persepsi yang positif terhadap kualitas pelayanan. Jadi, para staf dapat membantu para pelanggan dan memberikan pelayanan yang tanggap dalam memberikan layanan kepada pelanggan dalam hal ini tamu.

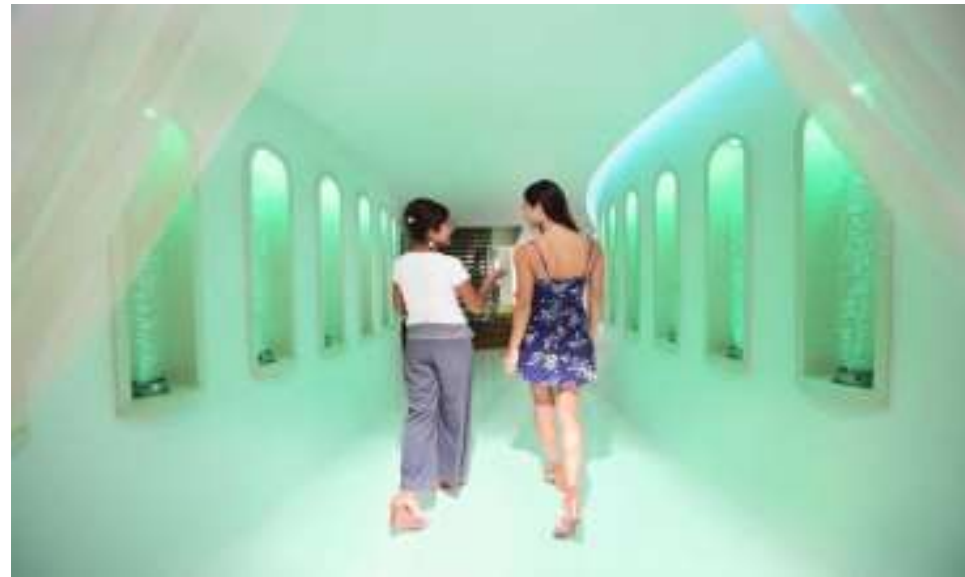

\section{Gambar 3.2 Daya Tanggap Pekerja Wanita Spa Saat Persiapan Penerimaan Tamu}

Sumber: Penelitian, 2018

Penerapan etika pelayanan dengan memberikan daya tanggap yang cepat dan tepat kepada tamu dapat membuktikan profesionalisme kerja pekerja wanita SPA di hotel tersebut. Hal ini akan diketahui apabila tamu pekerja SPA dapat mengerti dan memahami keinginan tamu tersebut serta dapat memulai layanan yang dimaksud dengan cepat dan tepat.

\section{Jaminan (assurance)}

Pengetahuan dan keramahan serta kemampuan melaksanakan tugas secara spontan yang dapat menjamin kinerja yang baik sehingga menimbulkan kepercayaan dan keyakinan pelanggan. Jadi, memberikan pengarah yang sesuai dengan pengetahuan yang dimiliki oleh pelayanan kepada pelanggan.

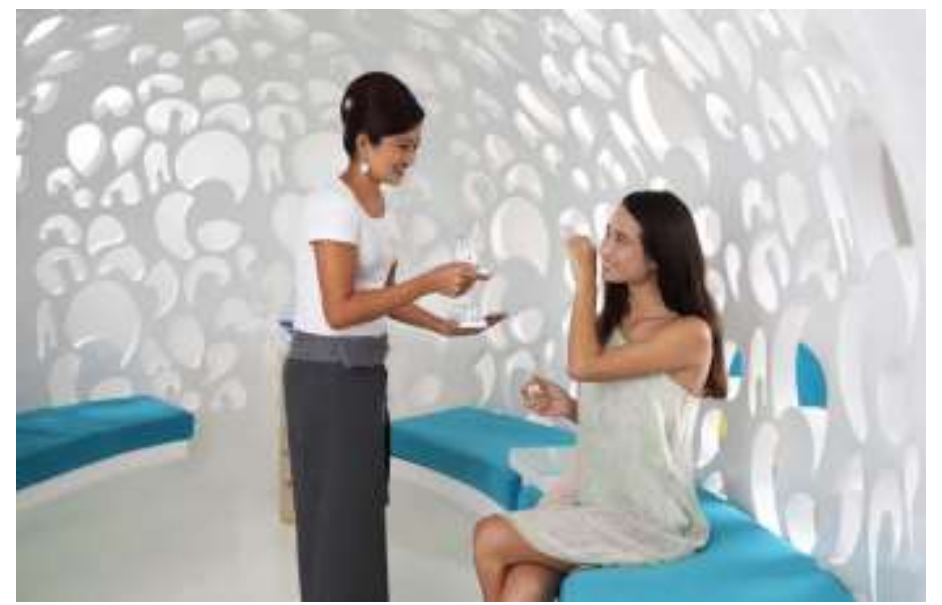

Gambar 3.3 Keramahan Pekerja Wanita Spa Saat Pelayanan Terhadap Tamu Sumber: Penelitian, 2018 
Pada gambar 3.3 menunjukkan seorang pekerja wanita SPA sedang memberikan pilihan aroma yang akan digunakan sebagai aroma therapy kepada tamu. Seorang pekerja wanita SPA diharapkan mengetahui kegunaan aroma tersebut sehingga tamu dapat memilih aroma tersebut dengan tepat. Pengetahuan terkait kegunaan aroma yang akan dipergunakan pada proses pelayanan harus dimiliki oleh perkerja SPA agar tamu tidak bingung dalam menentukan aroam yang teoat untuk proses pelayanan SPA.

\section{Empati (emphaty)}

Memberikan perhatian yang bersifat individual atau pribadi kepada pelanggan dan berupaya untuk memahami konsumen. Jadi, memberikan kemudahan dalam melakukan hubungan dengan pelanggan yang bersifat pribadi yang berupaya untuk memahami pelanggan yang datang. Pekerja wanita SPA harus memahami kebutuhan dan keinginan tamu sehingga dapat memberikan layanan yang tepat sesuai dengan kebutuhan tamu tersebut. Perhatian yang diberikan kepada semua tamu harus sama. Tamu yang datang secara berkala serta selalu memesan layanan SPA tertentu akan memudahkan pekerja wanita SPA memberikan pelayanan yang sesuai dengan keinginan tamu. Perhatian secara individual dapat ditunjukkan dengan berkomunikasi dengan tepat kepada tamu. Pekerja wanita SPA biasanya menanyakan kebutuhan dan keinginan apa yang sedang diinginkan oleh tamu. Dengan menanyakan hal tersebut, maka tamu menganggap bahwa pekerja tersebut akan melayaninya secara tepat sesuai kebutuhan dan keinginannya.

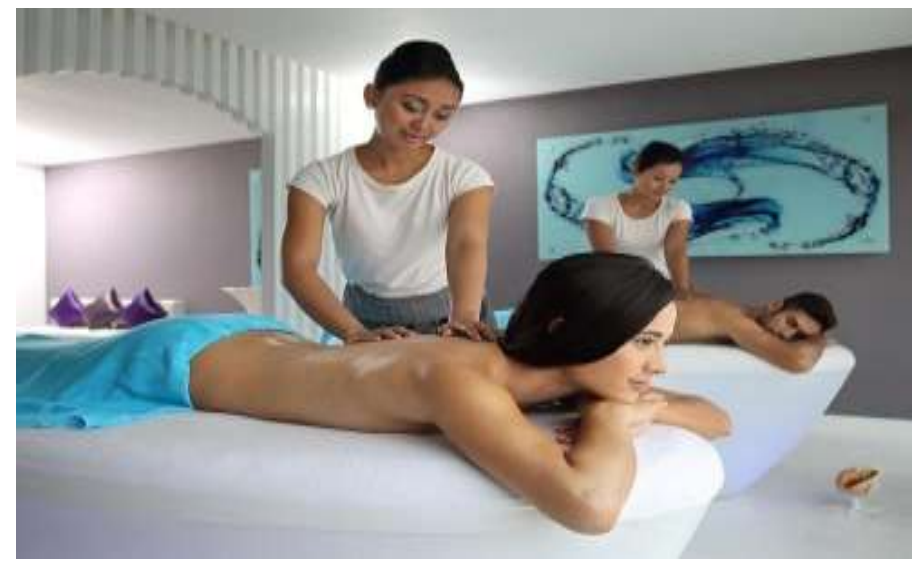

\section{Gambar 3.4 Kinerja Pekerja Wanita Spa Saat Pelayanan Terhadap Tamu}

\section{Sumber: Penelitian, 2018}

Pekerja wanita SPA memberikan perhatian sebagai upaya untuk meningkatkan kualitas pelayanan. Etika memberi perhatian yang tidak berlebihan akan membuat tamu merasa nyaman untuk berkunjung. Pemberian perhatian pada setiap tamu berbeda-beda disesuaikan dengan kondisi tamu masing-masing. Hal ini akan membuat tamu untuk datang kembali karena merasa puas atas layanan yang diberikan.

Meninjau keseluruhan aspek yang digunakan dalam menentukan model penerapan etika pelayanan pekerja wanita SPA pada hotel berbintang di Desa Adat Seminyak, berikut ini ditunjukkan melalui gambar 3.5. 


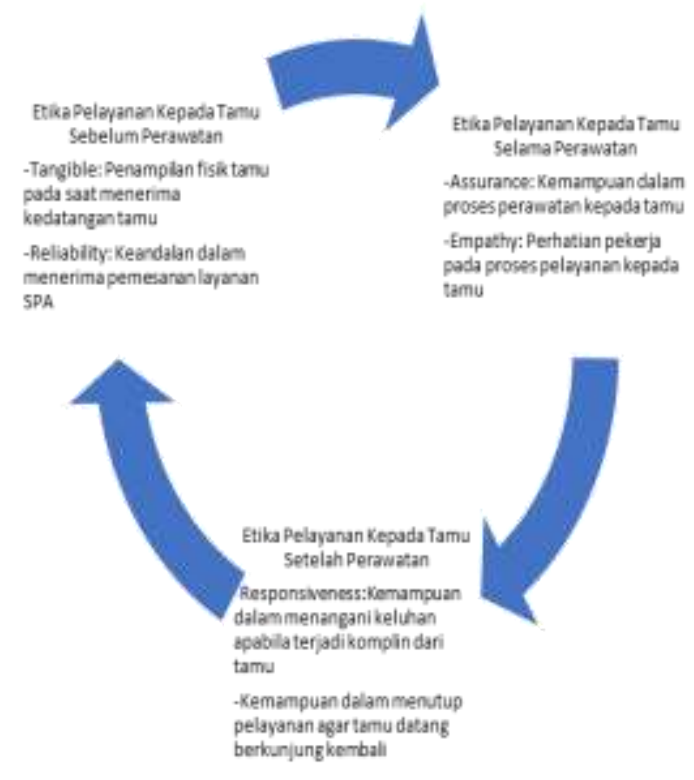

Ga mbar3.5 Model PenerapanEtika Pelayanan Pekerja Wanita SPAPada Hotel Berbintang Di Desa Adat Seminyak

Gambar 3.5 menunjukkan model penerapan etika pelayanan pekerja wanita SPA pada hotel berbintang di Desa Adat Seminyak. Model tersebut menunjukkan terdapat 3 tahapan dalam proses penerapan etika pelayanan, yaitu:

\section{Etika Pelayanan Kepada Tamu Sebelum Perawatan}

Pada proses ini etika pelayanan yang diterapkan antara lain:

- Tangible

Penampilan fisik pekerja wanita SPA adalah penting, mengingat hal ini dijadikan kesan pertama bagi tamu sebelum melakukan perawatan di SPA. Penampilan yang baik dan sopan menunjukkan bahwa kualitas pelayanan yang akan dinikmati selanjutnya akan berlangsung dengan baik. Apabila fisik pekerja wanita SPA ditunjukkan dengan baik dan sopaan maka tamu akan segera melakukan pemesanan perawatan di SPA tersebut. namun sebaliknya jika kesan pertama menunjukkan penampilan pekerja wanita SPA yang tidak baik dan tidak sopan maka tidak menutup kemungkinan calon pelanggan dalam hal ini tamu akan membatalkan pemesanan.

- Reliability

Keandalan dalam menerima pemesanan jenis perawatan yang diminta oleh tamu merupakan hal penting untuk diterapkan pada tahap sebelum perawatan. Etika menerima pemesanan perawatan harus dilakukan dengan baik dan sopan sehingga tamu merasa nyaman. Pemesanan yang dilakukan secara baik dan sopan akan menjadi kesan yang baik bagi calon tamu. Pada saat menerima pemesanan biasanya calon tamu akan menanyakan beberapa hal terkait pemesanan yang dilakukan. Sebaiknya pekerja wanita SPA memberikan jawaban yang tepat sehingga pemesanan yang dilakukan sesuai dengan harapan tamu.

\section{Etika Pelayanan Kepada Tamu Selama Perawatan}

Pada proses ini etika pelayanan yang diterapkan:

- Assurance

Penerapan etika pelayanan dengan menyajikan perawatan secara baik dan benar sangat dibutuhkan pada proses ini. Pekerja wanita SPA pada hotel berbintang kebanyak sudah sangat berpengalaman dan berpengetahuan di bidang SPA. Pengalaman diperoleh dari lamanya waktu kerja pekerja wanita SPA baik di hotel tersebut maupun hotel tempatnya bekerja terdahulu. Pengetahuan diperoleh dari 
berbagai pendidikan dan pengetahuan yang diperoleh pada bangku sekolah dan pelatihan-pelatihan yang dilakukan secara berkala.

- Empathy

Penerapan etika pelayanan melalui memberikan perhatian khusus kepada tamu atau pelanggan yang melakukan perawatan. Perhatian ini berbeda pada setiap individu tamu karena setiap tamu mempunyai karakter yang berbeda-beda. Bentuk perhatian yang berbeda namun tetap harus mengarah pada hasil kepuasan tamu yang sesuai. Bagi tamu yang memiliki penyakit khusus maka pekerja wanita SPA harus memberikan perhatian yang jauh lebih ketat dan disesuaikan dengan penyakit yang dimiliki.

\section{Etika Pelayanan Kepada Tamu Setelah Perawatan}

Pada proses ini etika pelayanan yang diterapkan adalah Responsiveness. Penerapan etika pelayanan dalam menutup penjualan dengan baik. Penutupan penjualan yang baik menentukan bahwa tamu tersebut akan datang atau tidak datang ke tempat tersebut kembali. Jika terdapat keluhan atau komplin dari tamu maka harus segera diselesaikan dengan cepat dan tepat. Penyelesaian keluhan yang tepat akan berakibat baik bagi keberlangsungan usaha namun jika tidak diselesaikan dengan baik maka akan berakibat buruk bagi keberlangsungan usaha.

\section{KESIMPULAN}

Hasil penelitian " Model Penerapan Etika Pelayanan Pekerja Wanita SPA Pada Hotel Berbintang Di Desa Adat Seminyak" dapat disimpulkan sebagai berikut: Model penerapan etika pelayanan pekerja wanita SPA pada hotel berbintang di Desa Adat Seminyak terdiri atas 3 tahapan, tahapan pertama yakni etika pelayanan tamu sebelum perawatan ditinjau dari aspek tangible atau fisik dan reliability atau keandalan. Pada tahapan ini lebih menekankan pada penerapan etika pelayanan pada saat tamu datang sebelum melakukan proses perawatan. Tahapan kedua yakni etika pelayanan tamu selama perawatan ditinjau dari aspek assurance atau jaminan dan empathy atau perhatian. Pada tahapan ini menekankan pada kemampuan dan perhatian sepanjang berlangsungnya proses pelayanan dalam hal ini perawatan SPA.Tahapan ketiga yakni responsiveness atau daya tanggap. Tahapan ini menekankan pada etika menutup penjualan dengan memberikan kesan akhir yang baik sehingga tamu akan berkunjung kembali melakukan perawatan SPA. Model penerapan etika pelayanan harus saling terkait agar pelaksanaan proses pelayanan dapat berlangsung dengan baik.

Penerapan etika pelayanan pekerja wanita SPA dapat ditingkatkan melalui beberapa hal seperti: pelatihan-pelatihan terkait dengan pelatihan etika agar pekerja wanita SPA mampu menerapkan etika pelayanan secara baik dan tepat, penerapan standar operasional prosedur pelayanan yang mengedepankan etika pelayanan. Penerapan etika pelayanan yang baik dan tepat akan menunjang kualitas pelayanan yang baik bagi departemen SPA di hotel tersebut. Pekerja wanita SPA pada hotel berbintang di Desa Adat Seminyak sebaiknya harus selalu menambah wawasan dan pengalaman dengan selalu belajar dari pelatihan-pelatihan terkait layanan SPA serta pendidikan formal lainnya yang sering diselenggarakan oleh dinas tenaga kerja. Pengalaman diperoleh melalui pekerjaan yang telah dilakukan sebelumnya serta belajar dari pengalaman senior atau rekan sekerja.

\section{DAFTAR PUSTAKA}

Alwi, Hasan. 2011. Kamus Besar Bahasa Indonesia. Jakarta: Gramedia Pustaka Utama. Bagyono. 2007. Pariwisata dan perhotelan. Cetakan Kedua. Bandung: Alfabeta Barata, Adya Atep. 2013. Marketing. Penerbit Ghalia. Jakarta, Indonesia. 
Bertens, K. 2000. Etika. Seri Filsafat Atma Jaya: 15. Jakarta: Penerbit PT Gramedia Pustaka Utama.

Bitner, Mary Jo, Zeithaml, Valarie A. 1996. Services Marketing. Edisi1. Boston. MCGraw-Hill.

Kasmir. 2008. Etika Customer Service. Jakarta: RajaGrafindo Persada.

Peraturan Menteri Kesehatan RI No. 1205/Menkes/X/2004 tentang pedoman persyaratan kesehatan pelayanan SPA.

Sihite, Richard. 2000. Hotel Management: Pengelolaan Hotel .Surabaya: SIC

Simorangkir. 2003. ETIKA : Bisnis, Jabatan, dan Perbankan. Jakarta : PT Rineka Cipta SK. Menteri perhubungan No. PM.10/ Pw. 301/ Phb.77 tentang pengertian hotel.

Tarmoezi, Trizno. 2000. Hotel Front Office. Jakarta: Kesaint Blanc

Undang-Undang Pariwisata No. 10 tahun 2009 tentang Kepariwisataan.

Bagus Ramadhan. Inilah 6 Operator Industri Pariwisata Terbaik Dunia Dari Indonesia Tahun 2017. https://www.goodnewsfromindonesia.id. Diakses pada 14 Juni 2018 18:04.

http://ejournal.unsrat.ac.id/index.php/politico/article/view/2581 (Rabu, 14 Juli 2018, pukul 20:15)

http://ejournal.unsrat.ac.id/index.php/politico/article/view/2581. Diakses pada 1 Juni 2018

Wikipedia,http://en.wikipedia.org/wiki/Spa. Diakses pada 10 Mei 2018

$\begin{array}{lllllll}\text { www.conectique.com. } & \text { Diakses } & \text { pada } & \text { tanggal } & 1 & \text { Juni } & 2018\end{array}$ 